\title{
Direct Analysis of Pharmaceutical Drugs Using Nano-DESI MS
}

\author{
Carlos Cardoso-Palacios and Ingela Lanekoff \\ Department of Chemistry-BMC, Uppsala University, Uppsala, Sweden \\ Correspondence should be addressed to Ingela Lanekoff; ingela.lanekoff@kemi.uu.se
}

Received 25 July 2016; Accepted 4 September 2016

Academic Editor: Sibel A. Ozkan

Copyright (C) 2016 C. Cardoso-Palacios and I. Lanekoff. This is an open access article distributed under the Creative Commons Attribution License, which permits unrestricted use, distribution, and reproduction in any medium, provided the original work is properly cited.

Counterfeit pharmaceutical drugs imply an increasing threat to the global public health. It is necessary to have systems to control the products that reach the market and to detect falsified medicines. In this work, molecules in several pharmaceutical tablets were directly analyzed using nanospray desorption electrospray ionization mass spectrometry (nano-DESI MS). Nano-DESI is an ambient surface sampling technique which enables sampling of molecules directly from the surface of the tablets without any sample pretreatment. Both the active pharmaceutical ingredients (APIs) and some excipients were detected in all analyzed tablets. Principal component analysis was used to analyze mass spectral features from different tablets showing strong clustering between tablets with different APIs. The obtained results suggest nano-DESI MS as future tool for forensic analysis to discern APIs present in unknown tablet samples.

\section{Introduction}

Falsifications of pharmaceutical drugs have increased together with the globalization and the worldwide percentage of all medicines which are counterfeit is estimated to be $10 \%[1,2]$. Counterfeit medicines can harm and kill and cause problems during treatment or recovery of the disease and even result in death. For example, fake vaccines caused 2500 deaths in Nigeria in 1995 [3], and an epidemic of fatal renal failure was a result of paracetamol elixirs containing diethylene glycol [4].

There are systems to prevent and control counterfeiting based on authentication characteristics. Among these technologies are barcodes, holograms, radio-frequency identification, digital watermarks, invisible printing, and chemical and biological tags [5]. Other approaches are mass serialization of the product and working towards a real global trade item number. Track and trace technologies are becoming more advanced, but they need still to be improved continuously and have to be used in a multilevel approach, in order to detect more sophisticated falsifications [5].

For chemical analysis, drugs may be analyzed by presumptive or confirmatory tests. Presumptive tests are typically on-field, fast, and easy to use. Many colorimetric assays, chemical as well as immunological, and thin layer chromatography (TLC) are popular presumptive techniques [6]. Confirmatory tests on the other side are slower but are more selective, precise, and accurate [1]. Techniques for confirmatory tests include different spectroscopy and separation techniques $[1,7-12]$. Separation techniques can be coupled to a variety of detection techniques, such as UV-visible detectors, flame ionization detector (FID), and electron capture detector (ECD), or mass spectrometry (MS) which also can provide a fingerprint of molecules present in the sample [13].

Direct MS analysis of tablets is possible using ambient surface sampled ionization techniques such as direct analysis in real-time (DART), desorption electrospray ionization (DESI), or surface desorption atmospheric pressure chemical ionization (DAPCI) [12, 14-17]. The benefit of these techniques is the immediate analysis of the molecular matrix on the tablet without the need for prior sample preparation or dissolution. A new ambient ionization technique for surface sampling is nanospray desorption electrospray ionization (nano-DESI) [18]. Nano-DESI utilizes two fused silica capillaries for extremely localized desorption of molecules from a surface into the continuously flowing liquid bridge between the capillaries. Nano-DESI hyphenated with MS has been employed in different applications such as mass spectrometry 
imaging (MSI) of molecules in thin tissue sections [19-26], bacterial characterization [27-29], direct analysis of crude petroleum [30, 31], and atmospheric samples [32-38].

Herein, we use nano-DESI MS for the first time to directly analyze fourteen different brands of tablets containing four different APIs, namely, ibuprofen, paracetamol, sildenafil (Viagra-type), or tadalafil (Cialis-type). By use of PCA we show that it is possible to cluster the tablets based on their APIs and their excipients.

\section{Material and Methods}

2.1. Tablets and Sample Preparation. Thirteen different brands of tablets and one gel were investigated; three contained ibuprofen, four contained paracetamol, four contained sildenafil, and three contained tadalafil. A table of all investigated tablets, their trade names, and amount API can be found in Table S1 in Supplementary Material available online at http://dx.doi.org/10.1155/2016/3591908. Some of the tablets were obtained from customs after being seized and some were bought fresh. The tablets were prepared by fracturing, which exposed a fresh surface for analysis. The fractured tablet was then manually placed under the nano-DESI probe using a micromanipulator (500 MIM, Quarter Research and Development, Bend, OR).

2.2. Nano-DESI MS Analysis. The nano-DESI probe was comprised of two fused silica capillaries $(50 \mu \mathrm{m}$ ID and $150 \mu \mathrm{m}$ OD, Polymicro Technologies, Molex) positioned at an angle to each other, as previously described [18]. A continuous flowing solvent, propelled at $1 \mu \mathrm{L} / \mathrm{min}$ using a syringe pump (Harvard Apparatus, Holliston, MA), generates a liquid bridge between the two capillaries. As the liquid bridge makes contact with the surface of the tablet, molecules are extracted into the solvent and transported to the inlet of the mass spectrometer for subsequent electrospray ionization and MS analysis. Three solvents were evaluated: methanol and water $(9: 1)$, methanol and water $(7: 3)$, and isopropanol and water $(9: 1)$. As no significant difference between the solvents was found, all analyses were performed using methanol and water $(9: 1)$. Data was acquired using a Q-Star XL (AB Sciex) in full MS mode, scanning between $\mathrm{m} / z 100$ and 2000 with a spray voltage of $3000 \mathrm{~V}$. The interface heater temperature was $200^{\circ} \mathrm{C}$, the ion sources gas 1 and 2 (GS1 and GS2) were set to 0 and the curtain gas (CUR) was set to 10 .

To continuously trace electrospray stability, an internal standard consisting of lysophosphatidylcholine (LPC) 19:0 was included in the nano-DESI solvent to a final concentration of $3 \mu \mathrm{M}$. The ions obtained from the standards were $\mathrm{m} / z$ 104 , which is a choline fragment, $m / z 538,560$, and 576 being LPC $19: 0[\mathrm{M}+\mathrm{H}]^{+},[\mathrm{M}+\mathrm{Na}]^{+}$, and $[\mathrm{M}+\mathrm{K}]^{+}$, respectively, and $m / z 1075$ which is an LPC 19:0 dimer.

2.3. Principle Component Analysis. Matrices of the acquired data from different tablets and replicates were constructed using the relative abundances of every detected ion. Ions originating from the internal standard, LPC 19:0, were excluded. Several technical replicates were obtained from each tablet

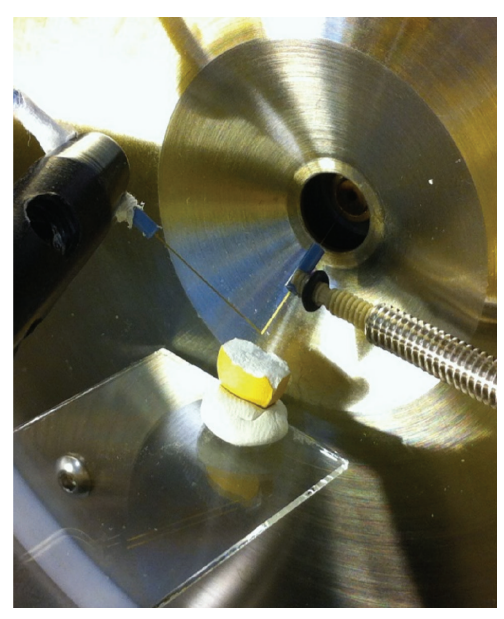

FIGURE 1: Photograph of the nano-DESI MS setup for online sampling and analysis from the surface of a fractured tablet.

as shown in Table S2. Data with a total ion current of at least $10^{4}$ counts per second and, at the minimum, one API or one excipient were included in the data matrix. The matrices were analyzed by principal component analysis (PCA) using The Unscrambler, version 9.7 (CAMO Software AS). The default settings were used, with leverage correction and the unweighted mode. The original variables were reduced to three principal components in the analysis.

\section{Results and Discussion}

Figure 1 shows a photograph of the nano-DESI MS setup for direct sampling from the tablet surface. The tablet was mounted on a glass slide which was manually moved into position using a micromanipulator. The four APIs could be readily detected with nano-DESI MS by simply dividing the tablet, positioning it under the liquid bridge, and allowing the liquid to come into contact with the surface of the tablet. Molecules from the tablet surface were readily desorbed into the nano-DESI solvent for subsequent electrospray ionization and MS detection.

Figures 2(a)-2(d) show four typical mass spectra from four different tablets. The detected ions corresponding to APIs are found in Table 1. The mass spectrum in Figure 2(a) is generated from an ibuprofen containing tablet. Ibuprofen is difficult to detect in positive mode but in this study a low abundant molecular ion was detected at $\mathrm{m} / z 207$. Additionally, Figure 2(a) shows peaks at $m / z 119$ and 161 which are attributed as ibuprofen fragment ions, corresponding to $\mathrm{C}_{9} \mathrm{H}_{11}$ and $\mathrm{C}_{12} \mathrm{H}_{17}$, respectively [39]. The mass spectrum in Figure 2(b) is generated from a paracetamol containing tablet. It shows the fragment ion of paracetamol at $m / z 110$, corresponding to $\mathrm{C}_{6} \mathrm{H}_{8} \mathrm{NO}$, and protonated paracetamol at $\mathrm{m} / z 152$ [40]. Additionally, paracetamol cationized on sodium was detected at low abundance at $m / z 174$. Figure 2(c) shows the mass spectrum from a sildenafil containing tablet with the peaks at $\mathrm{m} / \mathrm{z} 475$ and 513 corresponding to protonated sildenafil and sildenafil cationized on potassium, respectively. 


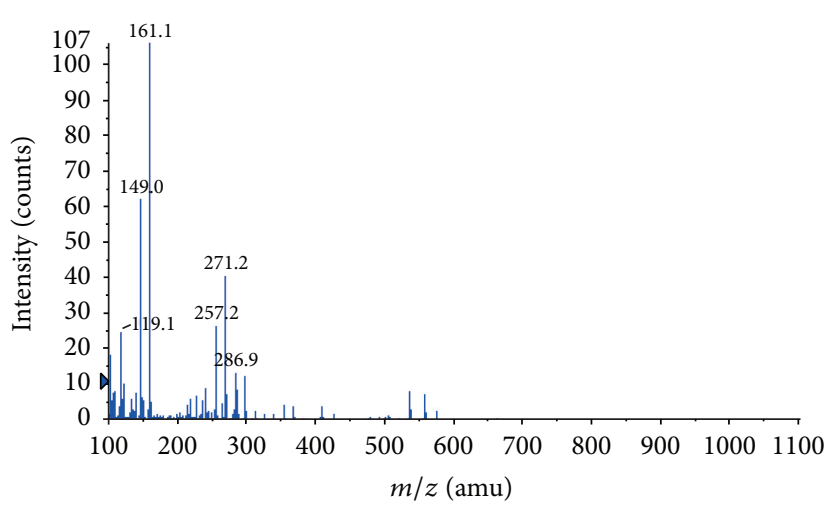

(a)

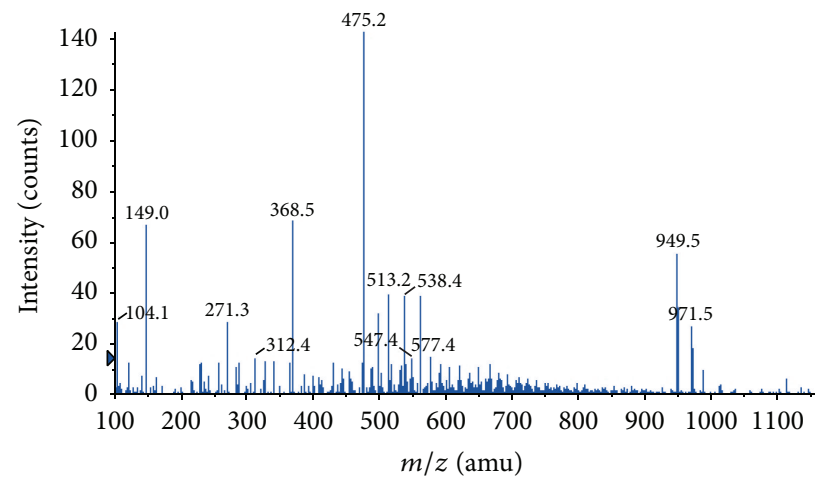

(c)

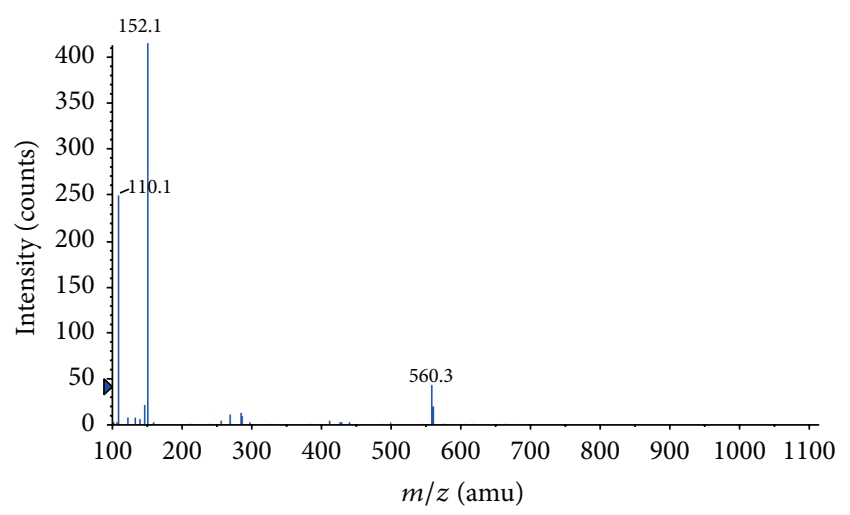

(b)

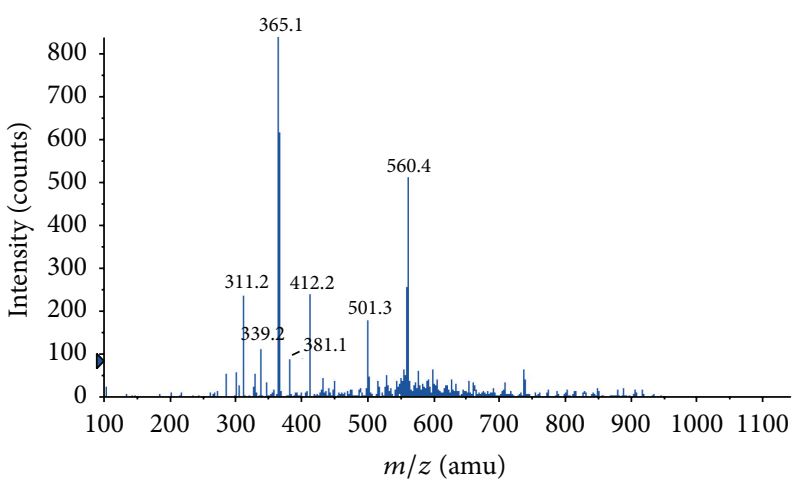

(d)

FIGURE 2: Mass spectra from direct tablet analysis using nano-DESI MS; (a) ibuprofen containing tablet, showing ibuprofen specific fragment ions at $m / z 119$ and 161, (b) paracetamol containing tablet, showing paracetamol specific fragment ions at $m / z 110$ and 152 , (c) sildenafil containing tablet, showing specific sildenafil $\mathrm{m} / z 475$ ion and $\mathrm{m} / z 513$ ion, and (d) tadalafil containing tablet, showing specific tadalafil $\mathrm{m} / z$ 412 ion and lactose $m / z 365$ ion.

Similarly, the peaks at $\mathrm{m} / z 949$ and 971 correspond to protonated and potassiated sildenafil dimers, respectively. These assignments are in agreement with previously published studies [41-44]. The mass spectrum acquired from a tablet containing tadalafil is shown in Figure 2(d). Peaks corresponding to tadalafil are found at $\mathrm{m} / z 268$ and 412, corresponding to a tadalafil fragment ion and the molecular ion of tadalafil cationized on sodium $[41,44,45]$. The signal intensity of tadalafil in Cialis-type tablets was lower than the other APIs analyzed. The signal intensities of APIs were similar between brand name and generic pharmaceutical drugs in all tablets analyzed. Additional, tentatively assigned, ions detected from the tablets and gel using nano-DESI MS were lactose $(\mathrm{m} / z 365)$ and glucose $(\mathrm{m} / z 203)$. These have also previously been detected using DESI MS [1]. Lactose is not an excipient in analgesic tablets but is present in both Viagraand Cialis-type tablets and detected in Cialis-type tablets. A notable exception of the Viagra-type samples was Kamagra which is a gel and contains both lactose and glucose, which are both detected.

Mass spectra generated by full-scan analysis of chemical compounds are typically very complex and consist of a large numbers of peaks. To simplify and understand the structure of the data acquired from the tablets, principal component analysis (PCA) was employed [46]. Figure 3

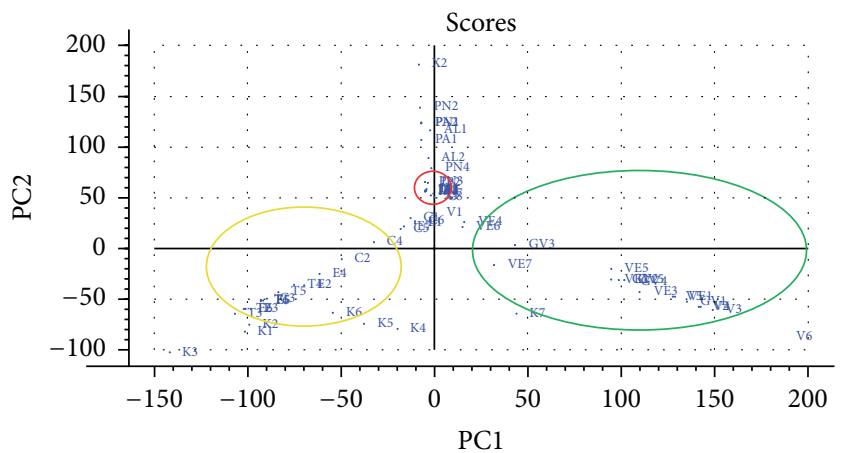

FIgURE 3: PCA scores of all samples. Matrix consisted of 63 samples and 112 ions. Important ions contributing to the new PCs according to the X-loadings are $m / z 110,152,365,366,475$, and 476 . The red circle shows ibuprofen containing medicines, the yellow circle shows tadalafil containing samples, and the green circle shows Viagra-type tablets.

shows the PCA scores for all samples using the two first principle components, $\mathrm{PCl}$ and $\mathrm{PC} 2$. The red ring circles the ibuprofen containing tablets which are mainly dependent on PC2. The yellow and green rings circle tadalafil containing tablets and the three different Viagra tablets, respectively. The latter are mainly separated based on PC1. APIs and/or lactose 
TABLE 1: APIs analyzed in this study, molecular formula, molecular weights, molecular structure, and detected $\mathrm{m} / \mathrm{z}$ ions with proposed adducts.

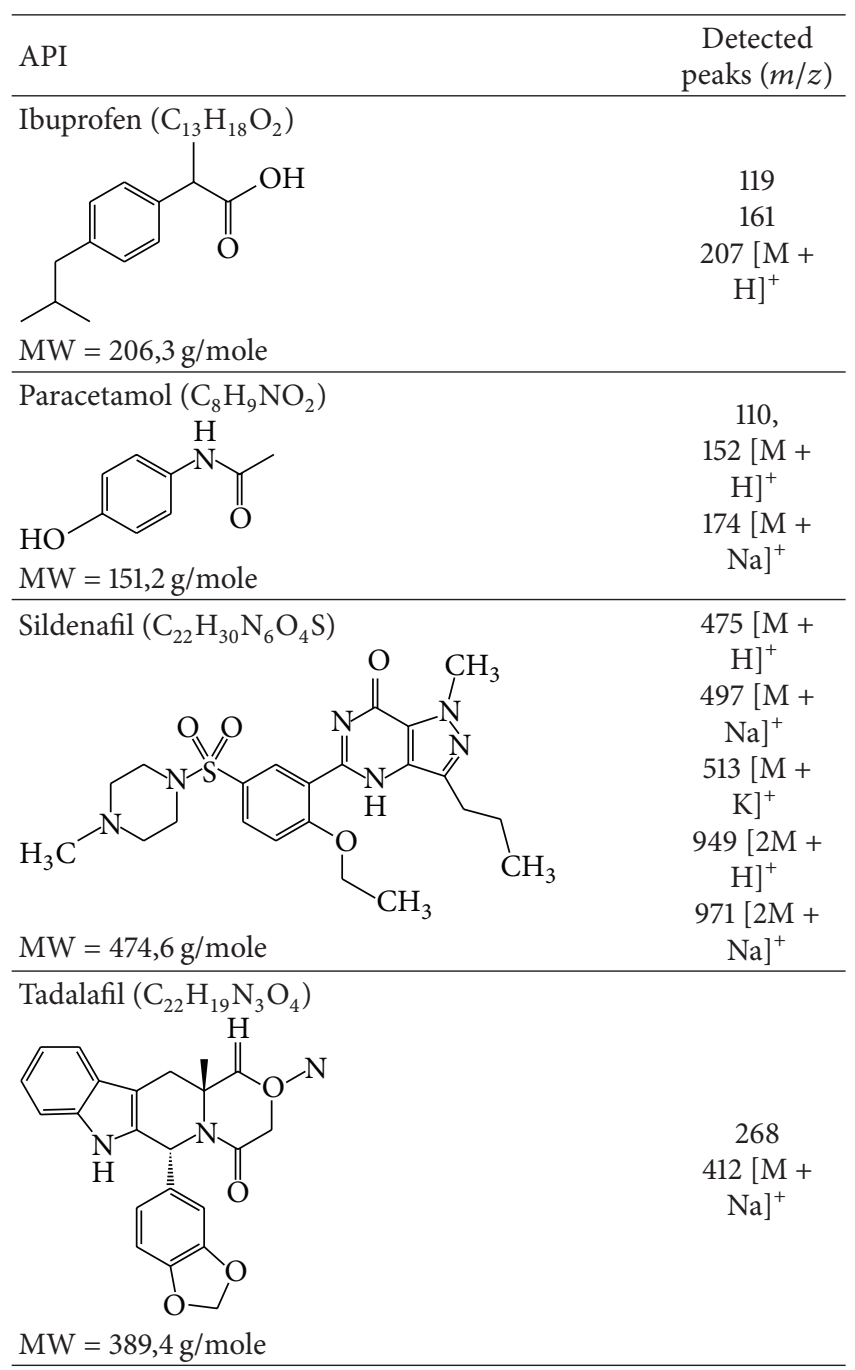

contributed greatly to the X-loadings, especially $m / z 110,152$, $365,366,475$, and 476 . This highlights the impact of APIs and implies potential problems when using PCA to discriminate between tablets having the same API. However, counterfeit drugs which do not contain the proper API will be easily distinguished. In addition, PCA can distinguish between pills containing different APIs. A high abundance of excipients can, however, cause a different clustering pattern which is not depending on APIs, as in the cases of Viagra and Kamagra. Viagra and Kamagra have the same API, but Kamagra is a gel with high lactose and glucose content which clusters it differently than Viagra as shown in Figure S1. By generating reference libraries of spectra from known tablets, nano-DESI MS in combination with PCA can be a tool to distinguish counterfeit and falsified pharmaceutical drugs.

In conclusion, thirteen different tablets, and one gel, with four different APIs were successfully analyzed with nano-DESI MS and clustered using PCA. The study shows that nano-DESI MS is a useful and powerful technique to detect APIs and excipients without the need for any sample preparation. The method has possibilities of automatization and quantification. No significant differences between seized and generic tablets were detected, but the technique could be further developed by coupling a more sensitive and higher resolving mass spectrometer nano-DESI enabling additional information about the tablet matrix to be obtained. Future perspectives of the use of nano-DESI MS as an anticounterfeit technology are quantification of APIs and excipients and tandem MS/MS analysis for increased accuracies and identifications. Additionally, reference libraries of spectra from known tablets can be used to rapidly find falsified or counterfeit tablets in a quest to limit harmful drugs in society.

\section{Competing Interests}

The authors declare that there is no conflict of interests regarding the publication of this paper.

\section{Acknowledgments}

The authors are grateful to Jenny Åberg and Martin Thoren from the Swedish Customs, Stockholm, Sweden, for providing the seized tablets and to Jean Pettersson at Uppsala University for fruitful discussions. Ingela Lanekoff acknowledges funding from the Swedish research council (VR 621-20134231) and the Swedish Foundation for Strategic Research (SSF ICA-6).

\section{References}

[1] R. Martino, M. Malet-Martino, V. Gilard, and S. Balayssac, "Counterfeit drugs: analytical techniques for their identification," Analytical and Bioanalytical Chemistry, vol. 398, no. 1, pp. 77-92, 2010 .

[2] E. Sukkar, "Taking stock of counterfeit medicines," The Pharmaceutical Journal, vol. 292, no. 7813, pp. 570-572, 2014.

[3] O. Akiny, "Counterfeit drugs in Nigeria: a threat to public health," African Journal of Pharmacy and Pharmacology, vol. 7, no. 36, pp. 2571-2576, 2013.

[4] M. Hanif, M. R. Mobarak, A. Ronan, D. Rahman, J. J. Donovan Jr., and M. L. Bennish, "Fatal renal failure caused by diethylene glycol in paracetamol elixir: the Bangladesh epidemic," British Medical Journal, vol. 311, no. 6997, pp. 88-91, 1995.

[5] D. Bansal, S. Malla, K. Gudala, and P. Tiwari, "Anti-counterfeit technologies: a pharmaceutical industry perspective," Scientia Pharmaceutica, vol. 81, no. 1, pp. 1-13, 2013.

[6] A. Negrusz and G. Cooper, Clarke's Analytical Forensic Toxicology, Pharmaceutical Press, 2nd edition, 2013.

[7] J. K. Maurin, F. Pluciński, A. P. Mazurek, and Z. Fijałek, "The usefulness of simple X-ray powder diffraction analysis for counterfeit control-the Viagra ${ }^{\circledR}$ example," Journal of Pharmaceutical and Biomedical Analysis, vol. 43, no. 4, pp. 1514-1518, 2007.

[8] P.-Y. Sacré, E. Deconinck, T. De Beer et al., "Comparison and combination of spectroscopic techniques for the detection of counterfeit medicines," Journal of Pharmaceutical and Biomedical Analysis, vol. 53, no. 3, pp. 445-453, 2010. 
[9] M. Park and S. Ahn, "Quantitative analysis of sildenafil and tadalafil in various fake drugs recently distributed in Korea," Journal of Forensic Sciences, vol. 57, no. 6, pp. 1637-1640, 2012.

[10] G. P. Sabin, V. A. Lozano, W. F. C. Rocha, W. Romão, R. S. Ortiz, and R. J. Poppi, "Characterization of sildenafil citrate tablets of different sources by near infrared chemical imaging and chemometric tools," Journal of Pharmaceutical and Biomedical Analysis, vol. 85, pp. 207-212, 2013.

[11] M. J. Vredenbregt, L. Blok-Tip, R. Hoogerbrugge, D. M. Barends, and D. D. Kaste, "Screening suspected counterfeit Viagra $^{\circledR}$ and imitations of Viagra ${ }^{\circledR}$ with near-infrared spectroscopy," Journal of Pharmaceutical and Biomedical Analysis, vol. 40, no. 4, pp. 840-849, 2006.

[12] L. Nyadong, G. A. Harris, S. Balayssac et al., "Combining twodimensional diffusion-ordered nuclear magnetic resonance spectroscopy, imaging desorption electrospray ionization mass spectrometry, and direct analysis in real-time mass spectrometry for the integral investigation of counterfeit pharmaceuticals," Analytical Chemistry, vol. 81, no. 12, pp. 4803-4812, 2009.

[13] P. Lebel, J. Gagnon, A. Furtos, and K. C. Waldron, "A rapid, quantitative liquid chromatography-mass spectrometry screening method for 71 active and 11 natural erectile dysfunction ingredients present in potentially adulterated or counterfeit products," Journal of Chromatography A, vol. 1343, pp. 143-151, 2014.

[14] Q. Hu, N. Talaty, R. J. Noll, and R. G. Cooks, "Desorption electrospray ionization using an Orbitrap mass spectrometer: exact mass measurements on drugs and peptides," Rapid Communications in Mass Spectrometry, vol. 20, no. 22, pp. 34033408, 2006.

[15] F. M. Fernández, R. B. Cody, M. D. Green et al., "Characterization of solid counterfeit drug samples by desorption electrospray ionization and direct-analysis-in-real-time coupled to time-of-flight mass spectrometry," ChemMedChem, vol. 1, no. 7, pp. 702-705, 2006.

[16] X. Zhang, B. Jia, K. Huang, B. Hu, R. Chen, and H. Chen, "Tracing origins of complex pharmaceutical preparations using surface desorption atmospheric pressure chemical ionization mass spectrometry," Analytical Chemistry, vol. 82, no. 19, pp. 8060-8070, 2010.

[17] H. Chen, J. Zheng, X. Zhang, M. Luo, Z. Wang, and X. Qiao, "Surface desorption atmospheric pressure chemical ionization mass spectrometry for direct ambient sample analysis without toxic chemical contamination," Journal of Mass Spectrometry, vol. 42, no. 8, pp. 1045-1056, 2007.

[18] P. J. Roach, J. Laskin, and A. Laskin, "Nanospray desorption electrospray ionization: an ambient method for liquidextraction surface sampling in mass spectrometry," Analyst, vol. 135, no. 9, pp. 2233-2236, 2010.

[19] I. Lanekoff, K. Burnum-Johnson, M. Thomas et al., "Threedimensional imaging of lipids and metabolites in tissues by nanospray desorption electrospray ionization mass spectrometry," Analytical and Bioanalytical Chemistry, vol. 407, no. 8, pp. 2063-2071, 2015.

[20] I. Lanekoff, K. Burnum-Johnson, M. Thomas et al., "High-speed tandem mass spectrometric in situ imaging by nanospray desorption electrospray ionization mass spectrometry," Analytical Chemistry, vol. 85, no. 20, pp. 9596-9603, 2013.

[21] I. Lanekoff, B. S. Heath, A. Liyu, M. Thomas, J. P. Carson, and J. Laskin, "Automated platform for high-resolution tissue imaging using nanospray desorption electrospray ionization mass spectrometry," Analytical Chemistry, vol. 84, no. 19, pp. 8351-8356, 2012.

[22] I. Lanekoff, S. L. Stevens, M. P. Stenzel-Poore, and J. Laskin, "Matrix effects in biological mass spectrometry imaging: identification and compensation," Analyst, vol. 139, no. 14, pp. 35283532, 2014.

[23] I. Lanekoff, M. Thomas, J. P. Carson, J. N. Smith, C. Timchalk, and J. Laskin, "Imaging nicotine in rat brain tissue by use of nanospray desorption electrospray ionization mass spectrometry," Analytical Chemistry, vol. 85, no. 2, pp. 882-889, 2013.

[24] I. Lanekoff, M. Thomas, and J. Laskin, "Shotgun approach for quantitative imaging of phospholipids using nanospray desorption electrospray ionization mass spectrometry," Analytical Chemistry, vol. 86, no. 3, pp. 1872-1880, 2014.

[25] J. Laskin, B. S. Heath, P. J. Roach, L. Cazares, and O. J. Semmes, "Tissue imaging using nanospray desorption electrospray ionization mass spectrometry," Analytical Chemistry, vol. 84, no. 1, pp. 141-148, 2012.

[26] H. Bergman, E. Lundin, M. Andersson, and I. Lanekoff, "Quantitative mass spectrometry imaging of small-molecule neurotransmitters in rat brain tissue sections using nanospray desorption electrospray ionization," The Analyst, vol. 141, no. 12, pp. 3686-3695, 2016.

[27] I. Lanekoff, O. Geydebrekht, G. E. Pinchuk, A. E. Konopka, and J. Laskin, "Spatially resolved analysis of glycolipids and metabolites in living Synechococcus sp. PCC 7002 using nanospray desorption electrospray ionization," Analyst, vol. 138, no. 7, pp. 1971-1978, 2013.

[28] J. Watrous, P. Roach, T. Alexandrov et al., "Mass spectral molecular networking of living microbial colonies," Proceedings of the National Academy of Sciences of the United States of America, vol. 109, no. 26, pp. E1743-E1752, 2012.

[29] J. Watrous, P. Roach, B. Heath, T. Alexandrov, J. Laskin, and P. C. Dorrestein, "Metabolic profiling directly from the petri dish using nanospray desorption electrospray ionization imaging mass spectrometry," Analytical Chemistry, vol. 85, no. 21, pp. 10385-10391, 2013.

[30] P. A. Eckert, P. J. Roach, A. Laskin, and J. Laskin, “Chemical characterization of crude petroleum using nanospray desorption electrospray ionization coupled with high-resolution mass spectrometry," Analytical Chemistry, vol. 84, no. 3, pp. 1517-1525, 2012.

[31] J. Laskin, P. A. Eckert, P. J. Roach, B. S. Heath, S. A. Nizkorodov, and A. Laskin, "Chemical analysis of complex organic mixtures using reactive nanospray desorption electrospray ionization mass spectrometry," Analytical Chemistry, vol. 84, no. 16, pp. 7179-7187, 2012.

[32] E. J. Boone, A. Laskin, J. Laskin et al., "Aqueous processing of atmospheric organic particles in cloud water collected via aircraft sampling," Environmental Science \& Technology, vol. 49, no. 14, pp. 8523-8530, 2015.

[33] J. M. Flores, R. A. Washenfelder, G. Adler et al., "Complex refractive indices in the near-ultraviolet spectral region of biogenic secondary organic aerosol aged with ammonia," Physical Chemistry Chemical Physics, vol. 16, no. 22, pp. 10629-10642, 2014.

[34] T. B. Nguyen, P. B. Lee, K. M. Updyke et al., "Formation of nitrogen- and sulfur-containing light-absorbing compounds accelerated by evaporation of water from secondary organic aerosols," Journal of Geophysical Research Atmospheres, vol. 117, no. 1, Article ID D01207, 2012. 
[35] R. E. O’Brien, A. Laskin, J. Laskin et al., "Molecular characterization of organic aerosol using nanospray desorption/electrospray ionization mass spectrometry: CalNex 2010 field study," Atmospheric Environment, vol. 68, pp. 265-272, 2013.

[36] L. Yu, J. Smith, A. Laskin, C. Anastasio, J. Laskin, and Q. Zhang, "Chemical characterization of SOA formed from aqueousphase reactions of phenols with the triplet excited state of carbonyl and hydroxyl radical," Atmospheric Chemistry and Physics, vol. 14, no. 24, pp. 13801-13816, 2014.

[37] L. Yu, J. Smith, A. Laskin et al., "Molecular transformations of phenolic SOA during photochemical aging in the aqueous phase: competition among oligomerization, functionalization, and fragmentation," Atmospheric Chemistry and Physics, vol. 16, no. 7, pp. 4511-4527, 2016.

[38] P. J. Roach, J. Laskin, and A. Laskin, "Molecular characterization of organic aerosols using nanospray-desorption/ electrospray ionization-mass spectrometry," Analytical Chemistry, vol. 82, no. 19, pp. 7979-7986, 2010.

[39] I. Ferrer and E. M. Thurman, "Measuring the mass of an electron by LC/TOF-MS: a study of 'twin ions"' Analytical Chemistry, vol. 77, no. 10, pp. 3394-3400, 2005.

[40] W. Weinmann, M. Stoertzel, S. Vogt, and J. Wendt, “Tune compounds for electrospray ionisation/in-source collision-induced dissociation with mass spectral library searching," Journal of Chromatography A, vol. 926, no. 1, pp. 199-209, 2001.

[41] S. R. Gratz, C. L. Flurer, and K. A. Wolnik, "Analysis of undeclared synthetic phosphodiesterase-5 inhibitors in dietary supplements and herbal matrices by LC-ESI-MS and LC-UV," Journal of Pharmaceutical and Biomedical Analysis, vol. 36, no. 3, pp. 525-533, 2004.

[42] S. R. Gratz, B. M. Gamble, and R. A. Flurer, "Accurate mass measurement using Fourier transform ion cyclotron resonance mass spectrometry for structure elucidation of designer drug analogs of tadalafil, vardenafil and sildenafil in herbal and pharmaceutical matrices," Rapid Communications in Mass Spectrometry, vol. 20, no. 15, pp. 2317-2327, 2006.

[43] C. N. Man, N. M. Nor, R. Lajis, and G. L. Harn, "Identification of sildenafil, tadalafil and vardenafil by gas chromatographymass spectrometry on short capillary column," Journal of Chromatography A, vol. 1216, no. 47, pp. 8426-8430, 2009.

[44] R. S. Ortiz, K. C. Mariotti, N. V. Schwab et al., "Fingerprinting of sildenafil citrate and tadalafil tablets in pharmaceutical formulations via X-ray fluorescence (XRF) spectrometry," Journal of Pharmaceutical and Biomedical Analysis, vol. 58, no. 1, pp. 7-11, 2012.

[45] M. E. Abdel-Hamid, "Determination of sildenafil, tadalafil, and vardenafil in tablets and adulterated herbal products by ESI-MS-MS," Journal of Liquid Chromatography and Related Technologies, vol. 29, no. 4, pp. 591-603, 2006.

[46] S. Bell, Forensic Chemistry, Pearson Education, Upper Saddle River, NJ, USA, 2nd edition, 2013. 

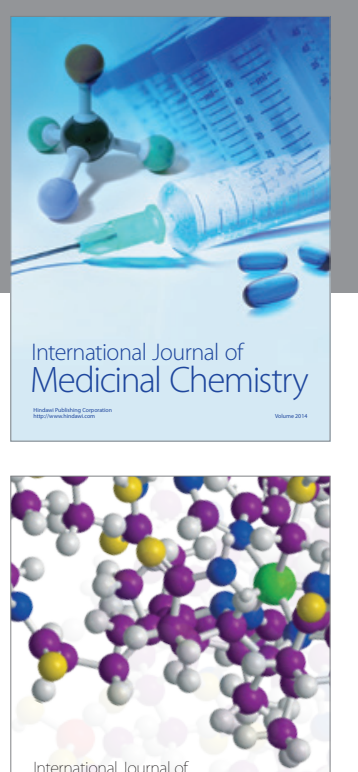

Carbohydrate Chemistry

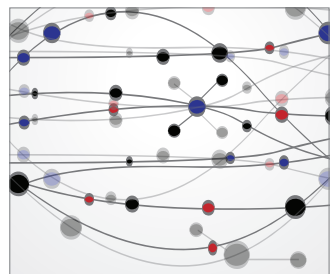

The Scientific World Journal
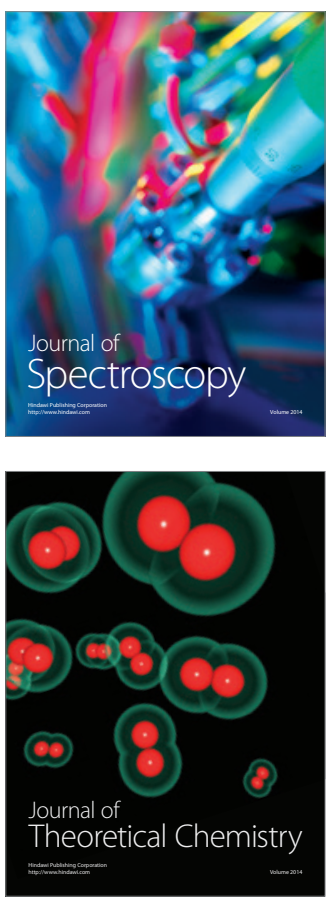
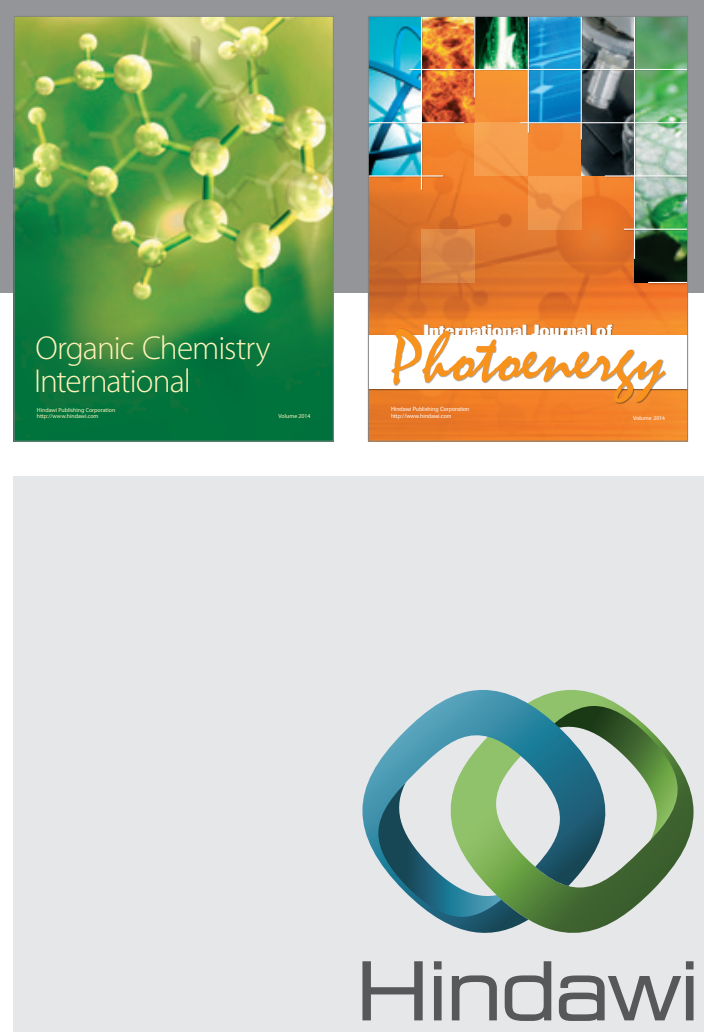

Submit your manuscripts at

http://www.hindawi.com

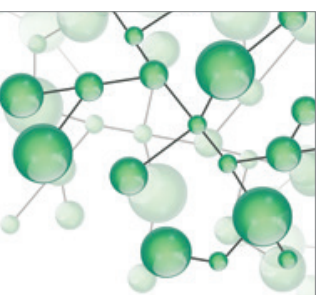

International Journal of

Inorganic Chemistry

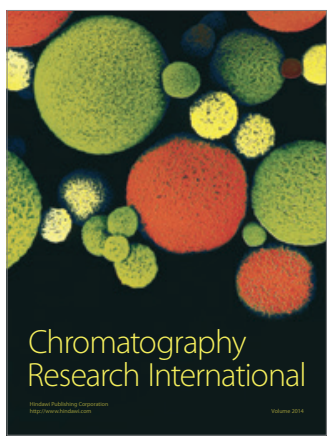

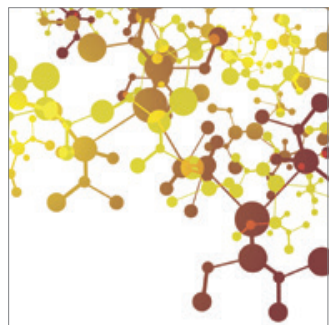

Applied Chemistry
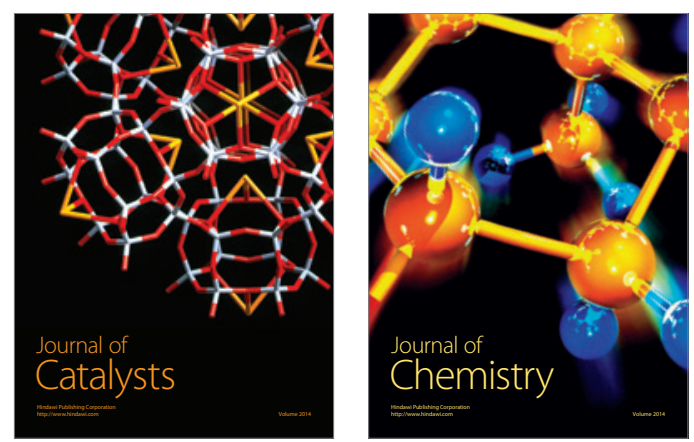
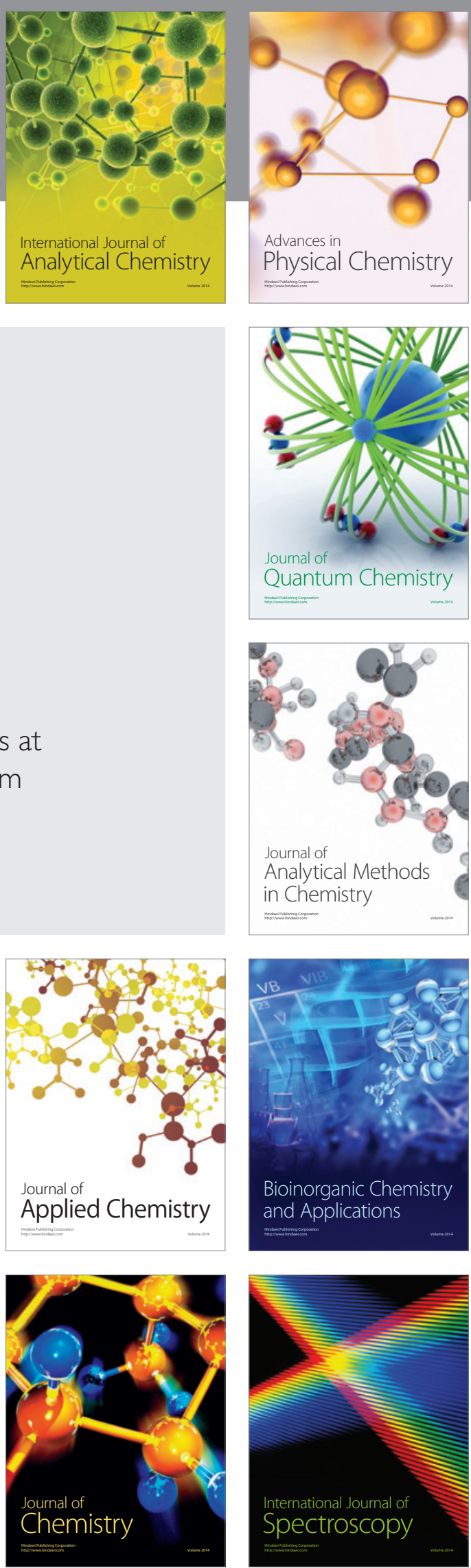